\title{
Hubungan Motivasi Perawatan Gigi Terhadap Kualitas Hidup Terkait Kesehatan Gigi (Oral Health Related Quality of Life - OHRQoL) Mahasiswa Fakultas Kedokteran Universitas Diponegoro
}

\author{
Ramadhika A. Zuhriza, ${ }^{1}$ Diah R. Wulandari, ${ }^{2}$ Tira H. Skripsa, ${ }^{1}$ Yoghi B. Prabowo ${ }^{1}$
}

\author{
${ }^{1}$ Departemen Kedokteran Gigi Fakultas Kedokteran Universitas Diponegoro, Semarang, \\ Indonesia \\ ${ }^{2}$ Departemen Kedokteran Fakultas Kedokteran Universitas Diponegoro, Semarang, Indonesia \\ Email: yoghibagusprabowo@lecturer.undip.ac.id
}

\begin{abstract}
The high number of dental and oral health problems is caused by lack of individual motivation to perform routine dental care, as seen from the number of people who receive treatment from the dentist is only $8.7 \%$. Serious oral health problems can lead to a decrease in the quality of life as well as work and study activities of an individual. This study was aimed to analyze the relationship between dental treatment motivation and Oral Health Related Quality of Life (OHRQoL) in students of the Faculty of Medicine, Diponegoro University. This was a descriptive and analytical study with a cross sectional design. Samples were choosen by using the cluster random sampling method. Data were analyzed by using the Spearman's rank correlation test. The results showed that the students had high motivation for dental treatment. Moreover, the students had good OHRQoL conditions, with the worse score on the dimensions of psychological discomfort, physical disability, social disability, and physical pain. The Spearman's rank correlation test obtained an r-value of 0.190 and a p-value of 0.020 for the relationship between dental treatment motivation and OHRQoL. In conclusion, there was a significant relationship between dental care motivation and OHRQoL in students of the Faculty of Medicine, Diponegoro University. The higher the dental treatment motivation, the better the quality of life is.
\end{abstract}

Keywords: motivation; dental treatment; OHRQoL; quality of life; OHIP-14

\begin{abstract}
Abstrak: Tingginya angka masalah kesehatan gigi dan mulut disebabkan oleh kurangnya motivasi individu untuk melakukan perawatan gigi secara rutin yang terlihat dari jumlah penduduk yang menerima perawatan dari tenaga medis gigi hanya $8,7 \%$. Masalah kesehatan yang ditemukan pada rongga mulut dan bersifat serius dapat menyebabkan terjadinya penurunan kualitas hidup individu serta aktivitas kerja dan belajar menurun. Penelitian ini bertujuan untuk menganalisis hubungan antara motivasi perawatan gigi terhadap kualitas hidup terkait kesehatan gigi (Oral Health Related Quality of Life - OHRQoL) mahasiswa Fakultas Kedokteran Universitas Diponegoro. Jenis penelitian ialah deskriptif analitik dengan desain potong lintang. Sampel penelitian dipilih dengan metode cluster random sampling. Data dianalisis menggunakan uji korelasi Spearman's rank. Hasil penelitian menunjukkan para mahasiswa memiliki motivasi perawatan gigi yang tinggi. Mahasiswa memiliki kondisi OHRQoL baik, dengan skor buruk pada dimensi ketidaknyaman psikis, disabilitas fisik, disabilitas sosial, dan rasa sakit fisik. Hasil analisis uji korelasi Spearman's rank memperoleh nilai $r=0,190$ dan nilai $p=0,020$ yang menunjukkan bahwa terdapat hubungan bermakna antara motivasi perawatan gigi dengan OHRQoL. Simpulan penelitian ini ialah terdapat hubungan bermakna antara motivasi perawatan gigi dengan OHRQoL pada mahasiswa Fakultas Kedokteran Universitas Diponegoro. Semakin tinggi motivasi perawatan gigi maka semakin baik kualitas hidup. Kata kunci: motivasi; perawatan gigi; OHRQoL; kualitas hidup; OHIP-14
\end{abstract}




\section{PENDAHULUAN}

Kualitas hidup ialah kondisi dimana seseorang merasakan adanya kenyamanan fisik, psikologi, sosial, dan spiritual yang memiliki manfaat dalam hidupnya secara optimal. ${ }^{1}$ Peningkatan kualitas hidup terkait kesehatan dapat dinilai dengan tiga komponen, yaitu mengidentifikasi kelainan patologik, melakukan pemeriksaan fungsi organ tubuh, serta menilai status kesehatan individu. Kesehatan gigi dan mulut (oral health) adalah kondisi pada rongga mulut yang terbebas dari rasa nyeri, kelainan kongenital, kerusakan gigi, serta penyakit periodontal lainnya. Adanya masalah kesehatan dalam rongga mulut dan bersifat serius akan menyebabkan terjadinya penurunan kualitas hidup individu. ${ }^{2}$

Kualitas hidup dipengaruhi oleh kesehatan gigi dan mulut karena manifestasi rongga mulut terhubung dengan seluruh kesehatan tubuh. ${ }^{3}$ Masalah gigi dan mulut sampai sekarang masih menjadi suatu permasalahan yang sering terjadi di masyarakat. Hal ini disebabkan oleh persepsi dan motivasi masyarakat dalam melakukan perawatan terhadap kesehatan gigi yang masih rendah. Mayoritas kesadaran masyarakat untuk melakukan perawatan gigi ialah setelah adanya keluhan rasa sakit yang terjadi pada rongga gigi ataupun jaringan sekitarnya. Tindakan perawatan gigi yang dapat dilakukan secara mandiri seperti menjaga kebersihan gigi dan mulut, mengonsumsi makanan yang baik untuk kesehatan gigi dan mulut, melakukan kompres, serta melakukan perawatan gigi secara rutin. ${ }^{4}$

Secara global tercatat bahwa angka kejadian masalah kesehatan gigi dan mulut mencapai $76 \% .^{5}$ Data yang diperoleh dari Riskesdas tahun 2018 menunjukkan bahwa angka prevalensi tingkat nasional terkait masalah kesehatan gigi dan mulut sebesar $25,9 \%$. Kelompok usia 15-24 tahun memiliki masalah kesehatan gigi dan mulut sebesar $51,9 \%{ }^{6}$ Tingginya angka tersebut disebabkan oleh kurangnya motivasi individu untuk melakukan perawatan gigi secara rutin yang terlihat dari persentase penduduk yang mendapatkan perawatan gigi oleh tenaga medis hanya sebesar $8,7 \% .^{6,7} \mathrm{Kon}-$ disi kesehatan gigi dan mulut yang buruk dapat mengganggu berbagai fungsi tubuh sehingga aktivitas kerja dan belajar menurun. ${ }^{8}$ Faktor-faktor yang dapat memengaruhi masalah kesehatan tersebut yaitu tingkat pendidikan, status sosial ekonomi, perilaku pola hidup sehat, dan motivasi masyarakat tentang kesehatan gigi dan mulut. Salah satu penyebab utama individu mengalami masalah kesehatan gigi dan mulut ialah kurangnya motivasi individu dalam melakukan perawatan sehingga mayoritas individu abai terhadap kebersihan gigi dan mulut. ${ }^{9}$

Motivasi dapat diartikan menjadi beberapa kata seperti kebutuhan (need), tekanan (urge), harapan (wish), dan dorongan (drive). Motivasi merupakan keadaan dalam individu yang dapat memberikan respon keinginan individu untuk melakukan tindakan tertentu yang bertujuan tercapainya harapan yang diinginkan. Faktor utama yang menjadi motivasi pasien untuk melakukan perawatan gigi yaitu estetika wajah. Estetika merupakan ekspresi wajah seseorang yang menggambarkan keadaan emosional dalam diri yang dapat memengaruhi kehidupan sosialnya. ${ }^{10}$

Motivasi perawatan gigi sendiri dipengaruhi oleh sikap, perilaku, dan pengetahuan tentang gigi. ${ }^{7}$ Hasil penelitian Sharda dan Shetty ${ }^{11}$ menunjukkan, bahwa paramedical students seperti farmasi dan perawat menunjukkan sikap dan perilaku kesehatan gigi yang lebih baik daripada medical students walaupun medical students memiliki tingkat pengetahuan yang tinggi.

Berdasarkan latar belakang ini terlihat bahwa kualitas hidup terkait kesehatan gigi merupakan salah satu aspek kesehatan yang sangat penting untuk diperhatikan. Kondisi ini diduga terkait dengan motivasi perawatan gigi pada mahasiswa Fakultas Kedokteran. Sampai saat ini belum pernah dilakukan penelitian yang menginvestigasi hal tersebut pada mahasiswa Fakultas Kedokteran Universitas Diponegoro. Hal ini mendorong penulis untuk menganalisis hubungan antara motivasi perawatan gigi terhadap kualitas hidup terkait kesehatan gigi (Oral Health Related Quality of Life OHRQoL) pada mahasiswa Fakultas Kedokteran Universitas Diponegoro 


\section{METODE PENELITIAN}

Jenis penelitian ini ialah analitik observasional dengan desain potong lintang. Populasi penelitian ini ialah mahasiswa Fakultas Kedokteran Universitas Diponegoro, sedangkan subyek penelitian ialah mahasiswa Fakultas Kedokteran Universitas Diponegoro Angkatan 2017.

Teknik pengambilan sampel menggunakan cluster random sampling. Tahap pertama ialah pengambilan seluruh program studi di Fakultas Kedokteran. Tahap kedua ialah pengambilan 150 responden, sesuai dengan perhitungan ukuran sampel. Tahap ketiga yaitu membagi jumlah responden pada tiap cluster atau program studi menggunakan rumus proporsional. Variabel yang diteliti ialah motivasi perawatan gigi menggunakan kuisioner Dental Treatment Motivation Scale (DTMS) dan variabel kualitas hidup terkait kesehatan gigi (OHRQoL) diukur menggunakan kuesioner WHO OHIP-14 dengan luaran data berskala kategorik.

Sebanyak 150 mahasiswa mengisi lembar informed consent. Motivasi perawatan gigi diukur menggunakan kuisioner DTMS sedangkan kualitas hidup diukur menggunakan kuesioner WHO OHIP-14. Data yang telah lengkap dianalisis menggunakan analisis korelasi Spearman rank untuk mengetahui hubungan antara motivasi perawatan gigi dengan OHRQoL.

\section{HASIL PENELITIAN}

Responden penelitian ini berjumlah 150 mahasiswa Fakultas Kedokteran Universitas Diponegoro Angkatan 2017 yang memenuhi kriteria inklusi dan eksklusi.

Tabel 1 memperlihatkan karakteristik responden penelitian berdasarkan jenis kelamin dan program studi. Responden penelitian ini ialah 150 mahasiswa dan jumlah responden pada masing-masing kelompok dihitung dengan rumus proporsional sehingga dapat menyajikan data masing-masing kelompok. Responden penelitian yang terbanyak ialah mahasiswa program studi kedokteran umum (55 dari total 150 mahasiswa) dan berjenis kelamin wanita (111 dari 150 mahasiswa).
Tabel 1. Karakteristik responden berdasarkan jenis kelamin dan program studi

\begin{tabular}{|c|c|c|c|}
\hline \multirow[b]{2}{*}{ Mahasiswa Undip } & \multicolumn{2}{|c|}{ Jenis Kelamin } & \multirow[b]{2}{*}{ Total } \\
\hline & Pria & Wanita & \\
\hline Kedokteran Umum & 27 & 28 & 55 \\
\hline Kedokteran Gigi & 6 & 15 & 21 \\
\hline Keperawatan & 1 & 29 & 30 \\
\hline Farmasi & 5 & 11 & 16 \\
\hline Gizi & 0 & 28 & 28 \\
\hline Total & 39 & 111 & 150 \\
\hline
\end{tabular}

Tabel 2 memperlihatkan distribusi berdasarkan motivasi perawatan gigi pada mahasiswa. Untuk kategori motivasi perawatan gigi rendah didapatkan jumlah responden ialah 0 pada seluruh kelompok program studi. Untuk kategori sedang didapatkan responden dengan persentase tertinggi $(11 \%)$ ialah pada kelompok mahasiswa kedokteran umum (6 responden). Untuk kategori tinggi didapatkan responden dengan persentase tertinggi (100\%) ialah kelompok mahasiswa kedokteran gigi (21 responden).

Tabel 2. Distribusi motivasi perawatan gigi mahasiswa Fakultas Kedokteran Universitas Diponegoro

\begin{tabular}{lcccc}
\hline \multirow{1}{*}{ Mahasiswa } & \multicolumn{3}{c}{ Motivasi } \\
& \multicolumn{2}{c}{ Tinggi } & \multicolumn{2}{c}{ Sedang } \\
& n & \% & n & \% \\
\hline Kedokteran Umum & 49 & 89 & 6 & 11 \\
Kedokteran Gigi & 21 & 100 & 0 & 0 \\
Keperawatan & 29 & 96,7 & 1 & 3,3 \\
Farmasi & 15 & 93,8 & 1 & 6,2 \\
Gizi & 27 & 96,4 & 1 & 3,6 \\
Jumlah & 141 & 94 & 9 & 6 \\
\hline
\end{tabular}

Tabel 3 memperlihatkan distribusi mahasiswa berdasarkan kualitas hidup terkait kesehatan gigi (OHRQoL). Untuk kategori kualitas hidup rendah didapatkan jumlah responden ialah 0 pada seluruh kelompok program studi. Untuk kategori kualitas hidup sedang didapatkan responden dengan persentase tertinggi $(9,1 \%)$ pada kelompok mahasiswa kedokteran umum 
(5 responden). Untuk kategori kualitas hidup tinggi didapatkan responden dengan persentase tertinggi $(100 \%)$ pada kelompok mahasiswa kedokteran gigi dan farmasi (21 responden dan 16 responden).

Tabel 3. Distribusi kualitas hidup terkait kesehatan gigi mahasiswa Fakultas Kedokteran Universitas Diponegoro

\begin{tabular}{lcccc}
\hline \multirow{1}{*}{ Mahasiswa } & \multicolumn{3}{c}{ OHRQoL } \\
& \multicolumn{2}{c}{ Baik } & \multicolumn{2}{c}{ Sedang } \\
& n & \% & n & \% \\
\hline Kedokteran Umum & 50 & 90,9 & 5 & 9,1 \\
Kedokteran Gigi & 21 & 100 & 0 & 0 \\
Keperawatan & 29 & 96,7 & 1 & 3,3 \\
Farmasi & 16 & 100 & 0 & 0 \\
Gizi & 26 & 92,9 & 2 & 7,1 \\
OHRQoL & 142 & 94,7 & 8 & 5,3 \\
\hline
\end{tabular}

Tabel 4 memperlihatkan bahwa OHRQoL pada mahasiswa Fakultas Kedok- teran didominasi kategori baik dan sedang pada setiap dimensi, dengan rincian 141 responden $(94,7 \%)$ OHRQoL baik dan 9 responden $(5,3 \%)$ OHRQoL sedang. Berdasarkan dimensi OHIP-14, kualitas hidup baik paling tinggi terdapat pada dimensi keterbatasan fungsional, disabilitas sosial dan keterhambatan dengan masing-masing 140 responden $(93,3 \%), 141$ responden $(94 \%)$, dan 140 responden $(93,3 \%)$ memiliki status OHRQoL yang baik. Kualitas hidup buruk paling tinggi terdapat pada dimensi ketidaknyaman psikis dan disabilitas fisik dengan masing-masing 2 responden (1,4\%).

Hasil analisis uji korelasi Spearman rank memperoleh nilai $\mathrm{r}=0,190$ dan nilai $\mathrm{p}=0,020$ yang menunjukkan bahwa terdapat hubungan bermakna antara motivasi perawatan gigi dengan kualitas hidup terkait kesehatan gigi (OHRQoL). Semakin tinggi motivasi perawatan gigi maka semakin baik kualitas hidup.

Tabel 4. Deskriptif dimensi OHIP-14

\begin{tabular}{lcccccc}
\hline \multicolumn{1}{c}{ Dimensi Kualitas Hidup } & \multicolumn{2}{c}{ Baik } & \multicolumn{2}{c}{ Sedang } & \multicolumn{2}{c}{ Buruk } \\
& n & \% & n & \% & n & \% \\
\hline Keterbatasan fungsional & 34 & 22,7 & 5 & 3,3 & 0 & 0 \\
$\quad$ Pria & 110 & 73,3 & 1 & 0,7 & 0 & 0 \\
$\quad$ Wanita & 33 & 22 & 6 & 0,4 & 0 & 0 \\
Rasa sakit fisik & 96 & 64 & 14 & 9,3 & 1 & 0,7 \\
$\quad$ Pria & & & & & & \\
$\quad$ Wanita & 31 & 20,7 & 8 & 5,3 & 0 & 0 \\
Ketidaknyamanan psikis & 71 & 47,3 & 38 & 25,3 & 2 & 1,4 \\
$\quad$ Pria & & & & & & \\
$\quad$ Wanita & 36 & 24 & 2 & 1,3 & 1 & 0,7 \\
Disabilitas fisik & 95 & 63,3 & 15 & 10 & 1 & 0,7 \\
$\quad$ Pria & & & & & & \\
$\quad$ Wanita & 31 & 22,7 & 8 & 5,3 & 0 & 0 \\
Disabilitas psikis & 93 & 60 & 18 & 12 & 0 & 0 \\
$\quad$ Pria & & & & & & \\
$\quad$ Wanita & 38 & 25,3 & 1 & 0,7 & 0 & 0 \\
Disabilitas sosial & 103 & 68,7 & 7 & 4,7 & 1 & 0,7 \\
$\quad$ Pria & & & & & & \\
$\quad$ Wanita & 33 & 22 & 6 & 4 & 0 & 0 \\
Keterhambatan & 106 & 70,7 & 5 & 3,3 & 0 & 0 \\
$\quad$ Pria & & & & & & \\
$\quad$ Wanita & 35 & 23,3 & 4 & 2,7 & 0 & 0 \\
OHRQoL & 107 & 71,3 & 4 & 2,7 & 0 & 0 \\
$\quad$ Pria & & & & & &
\end{tabular}




\section{BAHASAN}

Motivasi merupakan suatu kondisi internal yang dapat menghasilkan respon individu untuk melakukan tindakan, mendorong untuk mencapai target, serta merangsang diri untuk dapat tertarik dalam kegiatan tertentu. ${ }^{12}$ Hasil penelitian menunjukkan bahwa tingkat motivasi perawatan gigi pada mahasiswa Fakultas Kedokteran Universitas Diponegoro tergolong tinggi. Hal ini dapat dibuktikan dengan melihat Tabel 2 yang memperlihatkan tidak terdapat responden pada kategori tingkat motivasi perawatan gigi rendah. Sebanyak 141 responden $(94 \%)$ berada pada tingkat motivasi perawatan gigi tinggi. Hal ini menunjukkan bahwa mahasiswa Fakultas Kedokteran Universitas Diponegoro memiliki dorongan yang kuat pada dirinya untuk melakukan kegiatan merawat gigi. Faktor internal berupa persepsi individu mengenai diri sendiri, harga diri dan prestasi, harapan, kebutuhan, dan kepuasan merupakan faktor penting yang memengaruhi motivasi individu. ${ }^{13}$

Hasil penelitian menunjukkan bahwa 150 orang $(100 \%)$ setuju bahwa kesehatan gigi dan mulut sangat penting untuk berbagai aspek kehidupan. Menurut Khairani, ${ }^{13}$ individu akan mendapat dorongan untuk melakukan suatu tindakan atau respon dengan dipengaruhi oleh kognitif berupa persepsi. Persepsi yang dihasilkan akan mendorong dan mengarahkan individu tersebut untuk memberikan respon agar tercapainya tujuan. Hasil kuesioner menunjukkan bahwa 140 responden $(93,3 \%)$ setuju dan mempercayai bahwa merawat gigi merupakan hal terbaik untuk kesehatan. Hal ini juga ditunjukkan pada data penelitian, sebanyak 115 orang $(76,7 \%)$ setuju bahwa individu yang tidak merawat giginya akan merasa bersalah. Hasil tersebut sesuai dengan penelitian sebelumnya oleh Syrjala et $\mathrm{al}^{14}$ yang menyatakan motivasi intrinsik berperan besar dalam perilaku kesehatan.

Hasil penelitian oleh Walmsley menyatakan bahwa memberikan motivasi agar merawat gigi dengan baik dan benar, menjaga makanan yang dapat merusak gigi serta merekomendasikan pasien sesuai keadaan yang dialaminya, dapat mencegah timbulnya masalah kesehatan gigi dan membantu menjaga kesehatan gigi. ${ }^{7} \mathrm{Hal}$ ini ditunjukkan pada data hasil penelitian yaitu 113 responden $(75,3 \%)$ setuju bahwa dokter gigi meminta pasiennya untuk melakukan perawatan gigi.

Kepuasan adalah suatu dorongan yang bersifat afektif dari diri individu untuk memperoleh target atau tujuan yang diinginkan dari suatu perilaku. ${ }^{13}$ Hasil penelitian menunjukkan sebanyak 148 responden $(98,6 \%)$ setuju bahwa menjaga rongga mulut sebersih mungkin merupakan perasaan yang menyenangkan. Sehubungan dengan pertanyaan selanjutnya yaitu "apakah individu yang tidak merawat giginya akan merasa buruk?", hasil penelitian menunjukkan 121 responden $(80,7 \%)$ setuju. Hal ini selaras dengan penelitian yang dilakukan Kumar et al ${ }^{15}$ yang menyatakan responden pria dan wanita setuju bahwa merawat gigi dengan baik dan benar merupakan kepuasan tersendiri.

Berdasarkan kuesioner yang telah diberikan, jawaban negatif terbanyak terdapat pada item pertanyaan bahwa seseorang merawat gigi karena mendapat tekanan dari luar. Sebanyak 11 responden $(7,3 \%)$ merasa adanya tekanan dari orang sekitar untuk melakukan perawatan gigi dan 24 (16\%) lainnya ragu-ragu. Hal ini sejalan dengan penelitian sebelumnya oleh Oftedal ${ }^{16}$ yang menyatakan individu yang termotivasi karena rangsangan dari luar seperti dukungan keluarga, lingkungan dan sosial akan menciptakan suatu harapan yang dapat memengaruhi respon sehingga menghasilkan suatu sikap atau perilaku.

OHRQoL merupakan pengaruh kesehatan mulut pada pengalaman pribadi dan kepuasan yang berhubungan dengan kesehatan mulut pasien, kenyamanan saat makan, tidur, dan interaksi sosial. ${ }^{17}$ Hasil penelitian menunjukkan bahwa mahasiswa Fakultas Kedokteran Universitas Diponegoro didominasi oleh mahasiswa yang memiliki OHRQoL baik. Hal ini dapat dilihat pada Tabel 3 yang menunjukkan bahwa tidak ada responden dengan OHRQoL yang buruk. Sebanyak 142 (94,7\%) responden memiliki kualitas hidup yang baik. 
Hasil penelitian oleh Drachev et $\mathrm{al}^{18}$ menyatakan bahwa mahasiswa kedokteran gigi memiliki OHRQoL yang lebih baik daripada kedokteran umum; hal ini sesuai dengan hasil penelitian ini. Namun pada penelitian yang dilakukan oleh Drachev et $\mathrm{al}^{18}$ didapatkan bahwa lebih dari setengah responden $(53,6 \%)$ memiliki OHRQoL yang buruk, yang berbanding terbalik dengan hasil penelitian ini. Hal ini kemungkinan disebabkan karena evaluasi OHRQoL bergantung pada ekspektasi dan pengalaman individu yang bervariasi menurut faktor sosial, psikologis, sosial ekonomi, demografi, dan budaya lainnya. Seseorang dengan $\mathrm{OH}$ buruk dan ekspektasi rendah mungkin tidak menganggap dirinya memiliki OHRQoL rendah dan menyatakan dirinya puas. Sebaliknya, individu yang memiliki $\mathrm{OH}$ yang baik dan ekspektasi yang tinggi mungkin mengalami OHRQoL yang tinggi, bahkan karena masalah mulut yang kecil sehingga menyatakan tidak puas. ${ }^{19}$

Berdasarkan hasil penelitian yang dapat dilihat pada Tabel 4, jawaban negatif terbanyak "sering" dan "sangat sering" terdapat pada item pertanyaan ketidaknyaman psikis, disabilitas fisik, disabilitas sosial, dan rasa sakit fisik. Hasil tersebut sesuai dengan penelitian oleh Xavier ${ }^{20}$ yang menyatakan bahwa pada dewasa muda dimensi rasa sakit fisik dan ketidaknyamanan psikis sangat memengaruhi kualitas hidup. Apabila dibandingkan dengan pria, wanita cenderung merasa tidak puas dengan penampilan yang dimiliki dan wanita lebih mengekspresikan keluhan rasa sakit atau ketidaknyamanan dan ketidakmampuan untuk mengunyah. ${ }^{21,22}$ Kecenderungan wanita dalam mengekspresikan ketidakpuasan dengan penampilan, mengeluhkan rasa sakit, dan kesulitan mengunyah makanan dapat memengaruhi hasil penelitian. ${ }^{22}$

Hasil penelitian mendapatkan status OHRQoL tertinggi pada jenis kelamin wanita dengan status baik sebanyak 107 responden $(71,3 \%)$ dan status sedang sebanyak 4 responden $(2,7 \%)$. Hal ini mungkin disebabkan karena pada penelitian ini jumlah wanita lebih mendominasi daripada pria.

Hasil uji korelasi Spearman rank menunjukkan nilai kekuatan korelasi (r) sebesar 0,190 dan nilai $p$ sebesar 0,02 yang berarti terdapat hubungan bermakna antara motivasi perawatan gigi dengan kualitas hidup terkait kesehatan gigi (OHRQoL) pada mahasiswa Fakultas Kedokteran Universitas Diponegoro. Semakin tinggi motivasi perawatan gigi maka kualitas hidupnya juga semakin baik. Hal ini dikarenakan tingkat pendidikan dan pengetahuan dapat memengaruhi perilaku seseorang terhadap penyakit mulut. ${ }^{8}$ Semakin tinggi jenjang pendidikan maka pemanfaatan pelayanan medis juga semakin tinggi dan motivasi untuk berkunjung ke dokter gigi meningkat seiring dengan tingkat pengetahuan yang baik. 11,21,22

\section{SIMPULAN}

Pada mahasiswa Fakultas Kedokteran Universitas Diponegoro terdapat hubungan bermakna antara motivasi perawatan gigi dengan kualitas hidup, tingkat motivasi perawatan gigi yang baik, dan kondisi OHRQoL yang baik.

\section{Konflik Kepentingan}

Penulis menyatakan tidak terdapat konflik kepentingan dalam studi ini.

\section{DAFTAR PUSTAKA}

1. Tate RL. A compendium of tests, scales and questionnaires: The Practitioner's Guide to Measuring Outcomes After Acquired Brain Impairment. Psychology Press; 2020 Aug 13.

2. Baiju RM, Peter EL, Varghese NO, Sivaram R. Oral health and quality of life: current concepts. Journal of Clinical and Diagnostic Research (JCDR). 2017;11(6): ZE21.

3. Aryani R. Kesehatan Remaja Problem dan Solusinya. Jakarta: Salemba Medika, 2010; p. 227.

4. Pitts NB, Zero DT, Marsh PD, Ekstrand K, Weintraub JA, Ramos-Gomez F, et al. Dental caries. Nat Rev Dis Prim. 2017;25;3:17030. Doi: 10.1038/nrdp. 2017.30.

5. World Health Organization. Sugars and Dental Caries. Geneva: WHO, 2017. Available from: https://www.who.int/nutrition/ 
publications/nutrientrequirements/sugar s-dental-caries-keyfacts/en/

6. Riskesdas. Hasil Utama Riset Kesehatan Dasar (RISKESDAS) 2018. Available from: https://www.litbang.kemkes.go.id/hasil -utama-riskesdas-2018/

7. Lendrawati L. Motivasi masyarakat dalam memelihara dan mempertahankan gigi. Andalas Dental Journal. 2013;1(1):90101.

8. Utami S, Prasepti DI. Hubungan status karies gigi dengan oral health related quality of life pada mahasiswa. Insisiva Dental Journal (IDJ). 2019;8(2):46-52.

9. Mohammadi JJ, Franks K, Hines S. Effectiveness of professional oral health care intervention on the oral health of residents with dementia in residential aged care facilities: a systematic review protocol. JBI Evidence Synthesis. 2015;13(10):110-22.

10. Stretton-Downes S. Dental health. In: Kloos H, Zein ZA, editors. The Ecology of Health and Disease in Ethiopia (1st ed). Routledge, 2019.

11. Sharda AJ, Shetty S. A comparative study of oral health knowledge, attitude and behaviour of non-medical, para-medical and medical students in Udaipur city, Rajasthan, India. Int J Dent Hyg. 2010; 8(2):101-9.

12. Stoyanov S. A theory of human motivation. 2017. Doi:10.4324/9781912282517. Available from: https://www.research gate.net/publication/321006769_A_th eory_of_human_motivation

13. Khairani M. Psikologi Umum. Yogyakarta: Aswaja Pressindo, 2013.

14. Syrjälä AM, Kneckt MC, Knuuttila ML. Dental self-efficacy as a determinant to oral health behaviour, oral hygiene and HbA1c level among diabetic patients. J
ClinPeriodontol. 1999;26:616-21.

15. Kumar PS, Doshi D, Kulkarni S, Reddy P, Reddy S, Srilatha A. Effect of motivation on oral hygiene and caries status among young adults in Hyderabad City. Indian Journal of Dental Research (IJDR). 2019;30(1):15.

16. Oftedal BF. Motivation for self-management among adults with type 2 diabetes [Thesis]. Stavanger: University of Stavanger; 2011

17. Agustina D, Hanindriyo L, Widita E, Widyaningrum R. The correlation between occurrence of dental caries and oral health-related quality of life (OHRQoL) of elderly population in Yogyakarta Special Region. J Thee Med Sci. 2018; 50(2):2-3.

18. Drachev SN, Brenn T, Trovik TA. Oral healthrelated quality of life in young adults: a survey of Russian Undergraduate Students. Int J Env Res Pub Health. 2018;15(4):719.

19. Carr AJ, Gibson B, Robinson PG. Is quality of life determined by expectations or experience? BMJ. 2001;322(7296): 1240-3.

20. Xavier, A. Impact of dental caries on quality of life of adolescents according to access to oral health services: a cross sectional study. Braz J Oral Sci. 2016;15(1):1-7.

21. Ulinski KGB, Do Nascimento MA, Lima AMC, Benetti AR, Poli-Frederico RC, Fernandes KBP, et al. Factors related to oral health-related quality of life of independent Brazilian elderly. Int $\mathrm{J}$ Dent. 2013;2013:11-3.

22. Motallebnejad M, Mehdizadeh S, Najafi N, Sayyadi F. The evaluation of oral healthrelated factors on the quality of life of the elderly in Babol. Contemp Clin Dent. 2015;6(3):313-7. 